\title{
Using the Concepts and Tools of Social Ecological Systems and Ecosystem Services to Advance the Practice of Ecosystem-Based Management
}

\author{
Timothy G. O'Higgins, Theodore H. DeWitt, and Manuel Lago
}

\begin{abstract}
Environmental problems are very often wicked problems: they are persistent, they have no clear end, and involve moral choices resulting in winners and losers. Just as the ecological and biological elements of these problems are dynamic and complex, so the social and political elements are also constantly changing and do not follow linear patterns. Ecosystem-Based Management (EBM) is an approach developed to work on wicked problems that recognizes social-ecological systems and the need to incorporate systems thinking into natural resource management. In this chapter we describe the scope and scale of this book and briefly discuss its four sections:
\end{abstract}

- foundational concepts

- tools for the practice

- national and international governance contexts

- case studies.

We then go on to identify some of the main lessons learned, challenges and the main needs required to further advance the applications of EBM. We conclude with an exhortation for readers to learn from our experience, to use and adapt the tools and techniques we present here and a call for continued international collaboration.

\footnotetext{
T. G. O'Higgins ( $\square)$

Environmental Research Institute, University College Cork, Cork, Ireland

e-mail: tim.ohiggins@ucc.ie
}

T. H. DeWitt

Center for Public Health \& Environmental Assessment, US Environmental Protection Agency,

Newport, OR, USA

e-mail: dewitt.ted@epa.gov

M. Lago

Ecologic Institute, Berlin, Germany

e-mail: manuel.lago@ecologic.eu 


\section{The Problem}

Environmental problems are ubiquitous. At the local scale, human activities gradually supplant natural environments with local environmental consequences, and summing all these localised activities has resulted in global-scale crises in biodiversity and climate. These problems are vast in scale, can seem overwhelming, and have major consequences for human well-being. Destruction of aquatic ecosystems is of particular concern. Marine ecosystems, which make up the largest part of the globe, are coming under increasing pressure, and freshwater ecosystems are experiencing biodiversity loss more rapidly than their terrestrial counterparts (Dudgeon et al. 2007; Halpern et al. 2008; EEA 2010). It is easy to point fingers at human population growth, economic systems, industrial sectors, governments, and society as a whole for their role in the gradual but accelerating erosion of ecosystems, biodiversity, and the benefits they provide. Recognising the problems caused by degradation and destruction of the environment and identifying the social causes of environmental damage are essential in raising public awareness, but this is only the starting point for environmental management.

Environmental problems are very often wicked problems: they are persistent, they have no clear end, and involve moral choices resulting in winners and losers. Just as the ecological and biological elements of these problems are dynamic and complex, so the social and political elements are also constantly changing and do not follow linear patterns. For example, the phenomenon of eutrophication involves interactions between natural processes such as weathering, nitrogen fixation, decomposition and mineralisation, as well as anthropogenic factors such as wastewater discharge, fertilisation and animal feeds, all operating at different rates and over a range of spatial scales from catchment to ocean basin. While the processes and activities contributing to eutrophication may occur in one location, their effects may be felt in another, resulting in winners and losers from diverse sections of society including, for example, farmers and city dwellers who depend on different aspects of the environment (rivers, lakes, coastal zones) for a range of different uses from drinking water extraction to recreation, all of which are underpinned by biodiversity. To complicate matters further, these users may be in different jurisdictions regulated by different economic and political systems, and with different sets of values and economic needs.

While the early environmental movement typically focussed on humans and their impacts on the environment (e.g., Ehrlich 1968; Ehrlich and Holdren 1971; Hardin 1974), solutions tended to be simplistic. For example, Hardin (1968) identified the problem of the "Tragedy of the Commons", recognising the lack of incentive for conservation actions in the management of common pool resources and identifying assignation of ownership rights as a potential regulatory solution. More recent empirical studies on the factors leading to successful natural resource management regimes have led to the concept of Social-Ecological Systems, recognising that any given resource management problem is comprised of subsystems including resources, users, institutions and rules (Östrom 2009) and enabling the identification 
of characteristics of successful resource management regimes (Östrom 1990). While research into social-ecological systems has provided a very promising direction for improved environmental management and while the potential for this new, more holistic approach to environmental management, generally termed Ecosystem-Based Management (EBM), has been widely recognised, to date there has been limited progress in incorporating such practice into large scale policy. For example, the mid-term review of the European Biodiversity Strategy (EC 2015) indicates that the strategy is failing, largely due to the lack of inter- or transdisciplinary knowledge and suitable assessments to inform policy choices on ecosystem restoration options. Despite high-level international commitments to reverse declines in biodiversity under the Convention on Biodiversity, declines in environmental quality, biodiversity and ecosystem services are a global phenomenon.

The goal of this book is to examine the current state of the art of holistic and collaborative techniques to address wicked environmental problems through the application of Ecosystem Based Management, and describe how these techniques can be effectively implemented at multiple spatial scales.

\section{Emerging Solutions}

Ecosystem-Based Management (EBM) is an approach developed to work on wicked problems that recognises social-ecological systems and the need to incorporate systems thinking into natural resource management. EBM takes the perspective that human social systems are contained within and completely dependent on the broader ecological system, and works backwards from the problem to identify the causes and actors. EBM also recognises and incorporates the ecological complexity associated with environmental problems and the interdependencies of organisms (including humans) and ecological processes, as well as the potential for multiple interacting causes of specific problems. As a working definition, we consider that EBM "describes the comprehensive integrated management of human activities based on the best available scientific knowledge to achieve sustainable use of ecosystem goods and services and maintenance of ecosystem integrity" (Le Tissier 2020). There are many other definitions of EBM with a variety of different emphases; Delacámara et al. (2020) synthesize the high level characteristics that define EBM as a distinct management approach. A common factor in much of EBM is the inclusion of different stakeholders to understand the needs and behaviours of different groups, to identify trade-offs and develop consensus. In this book, we provide a snapshot of the current state of the art of EBM, including the main concepts, conceptual frameworks, tools, legal frameworks and specific examples of application to a range of different study sites, mainly from Europe and North America. This book marked a unique transatlantic collaboration, bringing together cutting-edge science from a range of EU research institutions under the umbrella of the AQUACROSS project and from the US EPA ecosystem research community. Our research was driven by a common need for ecosystem-based approaches to 
similar environmental problems. We recognised the value of bringing together our approaches and experiences. The authors of each chapter have identified key lessons and outcomes of their studies as they pertain to the development and implementation of EBM as well as key needs for the advancement and application of EBM.

\section{Structure}

The book is divided into four sections. Section 1 deals with foundational concepts such as the definition of EBM itself, the concept of ecosystem services, and the development of conceptual frameworks that connect human activities and ecosystem components. At the practical level, any effective management programme requires a clearly defined process and a series of discrete and replicable steps. When managing complex systems whose behaviour is not fully understood, the requirement for adaptive management, or "learning by doing" by which a cyclical management process can adapt to the changing conditions of the system (Holling 1978) has long been recognised. In this volume, based on experiences with implementation of EBM in the North Sea, Piet et al. (2020) set out their vision of an effective EBM process, which can provide a template for other areas. As with EBM definitions, a variety of standard processes have been put forward. DeWitt et al. (2020) describe a process of structured decision making designed specifically to enable the consideration of ecosystem services in EBM. While the choice of formal management systems may be dependent on the institutional and regulatory culture in a specific context, the management processes described by Piet et al. (2020) and DeWitt et al. (2020) share a number of common factors that set them apart from traditional management approaches and illustrate the emerging consensus on EBM best practices. Both studies follow the well-established Plan-Do-Check-Act cycle, and although the implementation, monitoring and evaluation steps are generic, the types of activities used during the Planning Phase are what characterise EBM and involve an holistic and inclusive perspective that is often stakeholder-led. These activities include a variety of models and techniques to connect different elements of social- ecological systems.

A particular challenge of systems approaches is the need to integrate knowledge from ecological and social sciences. Ecosystem service concepts and tools provide the analytical basis to connect the materials and processes of the ecological system with the needs and wants of the social system. Flood et al. (2020) introduce ecosystem services, providing an overview of the development of ecosystem services concepts and the promises and pitfalls of their application. Culhane et al. (2020) focus on the supply of all types of ecosystem services, with examples of how these concepts have been practically applied in a variety of different contexts. DeWitt et al. (2020), Russell et al. (2020) and Bousquin and Mazzotta (2020) each explore the relationship between the production of services by ecosystems and the subset of services that are directly used, enjoyed or appreciated by people, known as Final Ecosystem Goods and Services (FEGS). Understanding both the supply and 
demand side of ecosystem services is central to EBM; this is reflected in the "Butterfly" conceptual framework (Gómez et al. 2016; Delacámara et al. 2020; Elliott and O'Higgins 2020) employed throughout much of this volume. One commonly used framework, the Driver-Pressure-State-Impact-Response, has been widely used and adapted for the analysis of social-ecological systems. Elliott and O'Higgins (2020) describe the evolution of this framework as well as its latest adaptation, which has been applied in many of the studies presented here (e.g. Culhane et al. 2020; O’Higgins et al. 2020; Lillebø et al. 2020; McDonald et al. 2020).

Section 2 describes tools for ecological modelling, stakeholder engagement and analysis of ecosystem services that can support different steps along the EBM process. Tools to help implement EBM come in many forms. Linkage frameworks (Robinson and Culhane 2020) retain the complexity of human interactions while helping to elucidate the connections between human activities and environmental impacts, and can be extended to explore human effects and risks to ecosystem service supply. These linkage frameworks can provide a useful tool for exploring and communicating the complexity of social-ecological systems, particularly in situations where quantitative data are scarce. Ecological models can provide more quantitative approaches connecting ecosystem condition to the production of ecosystem services and their benefits. Developing and applying such models can be a complex and challenging process. Fulford et al. (2020) provide insights into the process of model development and many other chapters provide examples of model applications that vary in their data requirements, modelling approaches and complexity (e.g., Funk et al. 2020; O’Higgins et al. 2020; Lillebø et al. 2020). Decision support systems can be used to integrate multiple models, and include ENVISION, explored by McKane et al. (2020), ARIES and InVEST (Lewis et al. 2020; Funk et al. 2020; Lillebø et al. 2020). Many of the chapters in the tools section, which focus on demand side aspects of the EBM process, have a particular focus on transparency and replicability (e.g., Sharpe et al. 2020; Russell et al. 2020). This focus is of particular importance for mainstreaming of EBM, where subjective human values, as well as objective, measurable ecological parameters, are involved in public decision making.

Decision contexts for environmental problems are location specific; understanding the legal basis and background of environmental law both enables and sets constraints on the scope of management. Section 3 deals with the International, US and European basis for the governance of social-ecological systems. Enright and Boetler (2020), O'Hagan (2020) and Harwell (2020) explore the legal and institutional context for EBM internationally, within Europe and in the US respectively, while Le Tissier (2020) explores how the legal origins of related management approaches and tools, such as integrated coastal zone management and marine spatial planning, have shaped understanding of EBM. The international conventions and treaties that have given rise to the prominence of the EBM concept play out in different ways between European and US jurisdictions. Understanding these institutional contexts is also vital in the selection of appropriate tools that can support policies and practices at national and local scales. 


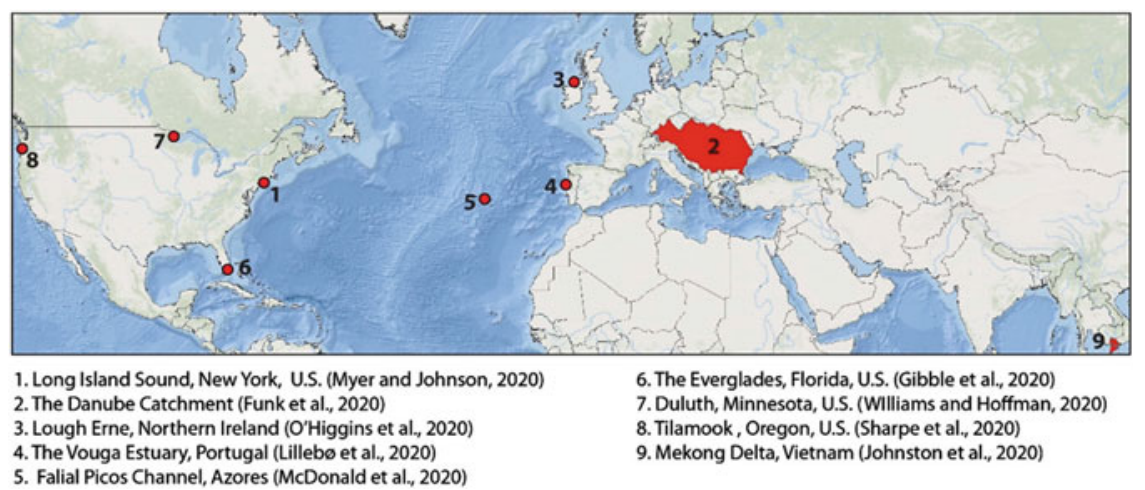

Fig. 1 The geographic diversity of place-based studies addressed in this volume

Section 4 brings together a selection of cutting-edge case studies of EBM from diverse geographic and environmental settings (Fig. 1), from the Great Lakes of North America to the Mekong Delta in Vietnam, from marine and estuarine systems to freshwater rivers, lakes and wetlands of the Danube catchment (the most international river basin in the world).

These case studies explore the approaches and challenges of implementing EBM and they range from simple, but effective, common-sense, mapping and communication of ecosystem services (Myer and Johnston 2020) to applications of highly sophisticated ecological models. For example, a more sophisticated model might use artificial intelligence combined with Geographic Information Systems to generate practical management solutions (Funk et al. 2020) or complex statistical techniques to integrate ecosystem services into long-term climate adaptation (Johnston et al. 2020). Some case studies illustrate how approaches to EBM have evolved over time, adapting and bringing together several strands of existing activity (e.g., Gibble et al. 2020; Williams and Hoffman 2020; Funk et al. 2020), others describe initial steps toward integration of ecosystem services into resource management (Lilleb $\emptyset$ et al. 2020). In data-rich cases, different methodologies have been tested on the same system (e.g., Funk et al. 2020), whereas in data-poor cases, simple stakeholder opinions on system function have been used to develop models that can inform ecosystem management (O’Higgins et al. 2020).

\section{Lessons Learned}

Overall, the various tools, techniques and case studies demonstrate a variety of parallel approaches to developing ways of managing complex, adaptive socialecological systems. In combination, these studies have revealed a number of important key lessons learned. 


\section{- Mixing models and multidisciplinary approaches}

EBM requires inputs from multiple disciplines each with their own tools and techniques. Methods for combining models of different sub-systems within the social-ecological system are vital to EBM, but the types of models best employed depends on the availability of data and expertise. One size doesn't fit all; however, the toolbox of methods highlighted in this book are usable across a wide range of decision contexts and problem complexities, ecological and social settings, and spatial and temporal scales. Suitable tools range from the highly detailed, complex and computationally intensive models to simple box and arrow models based on expert opinion. The best model or approach is context dependent.

- Include diverse stakeholders in all stages of problem formulation and assessment of solutions

Many different groups are affected by environmental decisions and successful EBM can elicit and incorporate information from different stakeholders to develop socially acceptable solutions. The appropriate types of information are required to communicate with appropriate stakeholders. While environmental information may be most important to conservationists, economic values can be persuasive tools in the development of management options.

\section{- Recognition of ecosystem services}

Understanding the links between human welfare and ecosystem integrity is a vital component of EBM, and explicit consideration of ecosystem services, whether focussed specifically on those providing direct human benefits (and their valuation) or qualitative assessments including the full suite of all ecosystem services, offers a means of incorporating these considerations into management. Valuation can be extremely useful but is not the only aim of ecosystem services assessment.

\section{- Problem specific solutions}

Each social-ecological system is unique, and the type of management best suited to each system depends on the characteristics of the system itself. Deploying a subset of tools and techniques best suited to a particular situation can enable problem specific management solutions, but requires consideration of the amount and type of data, as well as the social and ecological context.

\section{Challenges and Needs to Advance EBM}

EBM is an evolving field and in need of new knowledge and methods to further its success. At the beginning of each chapter, authors have identified up to three "needs for advancing EBM".

Several of the governance chapters point to the need for enhanced clarity as to what the process of EBM entails, standardisation of EBM approaches, the provision 
of guidance and a clarification of EBM concepts (Enright and Boetler 2020; O'Hagan 2020; Le Tissier 2020). This need for clarity is also reflected in many of the chapters describing tools, as well as in case studies (e.g., Harwell et al. 2020; Sharpe et al. 2020; Lewis et al. 2020), which advocate for structured and documented methods for incorporating specific aspects of EBM into practice.

Several of the European case studies identified the need for harmonisation and coordination of policy objectives across major European Directives (O'Hagan 2020; Lillebø et al. 2020) to develop more integrated approaches to food security and environmental conservation. Integration of EBM with administrative and legal frameworks can help embed EBM into mainstream environmental management. On the one hand, there is a role for scientists in defining EBM, to this end, standardized methodologies such as those described here (e.g. Piet et al. 2020) may help; on the other hand, there is an onus on scientists to understand and adapt to the legal frameworks set down. How can decision makers be expected to use EBM when it is poorly defined in law? The chapters in Section 3 illustrate that laws and environmental directives are often not well integrated and this may result from the legacy of single sectoral approaches. Harmonization of the new more holistic scientific approach with the practice and policy of natural resource management needs to be achieved if EBM is to become widely adopted.

This need for standardisation and harmonisation, to a certain extent, leads to a tension with the need for a stakeholder-driven process. Lilleb $\varnothing$ et al. (2020), McDonald et al. (2020), Williams and Hoffman (2020) and O'Higgins et al. (2020) all stress the requirement for co-design of the EBM process in collaboration with stakeholders and the development of problem-specific solutions. In the situation where every social-ecological system is different, comprised of unique ecological, social and political contexts and characteristics, the flexibility of stakeholder driven processes enables the development of unique solutions to unique (wicked) problems. At the same time, this requirement for flexibility inhibits our ability to proscribe one-size-fits-all standardised methodology. This situation requires a clear set of logical steps, which can be conducted in a flexible fashion. To this end, we hope that the tools and cases presented here can provide some examples that can be organised and re-arranged to meet practical management needs and conditions.

In order to embed EBM in practical natural resource management, there is a clear need for improved communication and capacity building, and this is identified by several authors herein (Russell et al. 2020; Myer and Johnston 2020; Williams and Hoffman 2020). Harwell et al. (2020) directly address the issues of strategic communication with respect to individual projects. The issue of capacity will require learning-by-doing, and we hope that our experiences in developing tools and applying methodologies will provide useful examples and ideas for future applications. 


\section{Conclusions}

While the studies in this book illustrate that there is an emerging consensus amongst experts in best practices for EBM, there is room for improvement in the development of methods to implement EBM. Though considerable progress has been made in development of techniques and tools for developing stakeholder consensus, for incorporating multiple values into management, and for modelling and predicting flows of ecosystem services, embedding these practices into standardised practical methodologies that meet conservation and legislative standards remains a major challenge. This will require redoubling of effort and can no doubt be enhanced by similar collaborations in the future.

We have found that our research has been considerably enriched by identifying similar EBM initiatives being conducted under different social and institutional settings. We were pursuing parallel paths and recognised that by bringing together the parts and their applications, we could identify emerging best practices that are beginning to define the science of EBM. While the complexity of addressing socialecological systems and the challenges of multi-disciplinary research may seem daunting, we encourage readers to embrace the idea of adaptive management, of learning-by-doing. Many of the techniques and tools identified here are low cost or open source and can be applied to an array of environmental challenges. Each of the tools and case studies presented has particular strengths. Readers considering the implementation of EBM practices are encouraged to identify areas where these tools can be combined in new ways to complement each other. We encourage the reader to follow the links to the various tools, to play with and familiarise themselves with their capabilities and to contact the authors who are (mostly!) approachable. We hope that they can, as we have, develop a new understanding of the power and promise of holistic Ecosystem-Based Management.

Disclaimer This chapter has been subjected to Agency review and has been approved for publication. The views expressed in this paper are those of the author(s) and do not necessarily reflect the views or policies of the U.S. Environmental Protection Agency.

\section{References}

Bousquin, J., \& Mazzotta, M. (2020). Rapid benefit indicator tools. In T. O’Higgins, M. Lago, \& T. H. DeWitt (Eds.), Ecosystem-based management, ecosystem services and aquatic biodiversity: Theory, tools and applications (pp. 309-332). Amsterdam: Springer.

Culhane, F. E., Robinson, L. A., \& Lilleb $\varnothing$, A. I. (2020). Approaches for estimating the supply of ecosystem services: Concepts for ecosystem-based management in coastal and marine environments. In T. O'Higgins, M. Lago, \& T. H. DeWitt (Eds.), Ecosystem-based management, ecosystem services and aquatic biodiversity: Theory, tools and applications (pp. 105-126). Amsterdam: Springer.

Delacámara, G., O'Higgins, T., Lago, M., \& Langhans, S. (2020). Moving from concept to practice. In T. O’Higgins, M. Lago, \& T. H. DeWitt (Eds.), Ecosystem based-management, ecosystem 
services and aquatic biodiversity: Theory, tools and applications (pp. 39-60). Amsterdam: Springer.

DeWitt, T. H., Berry, W. J., Canfield, T. J., Fulford, R. S., Harwell, M. C., Hoffman, J. C., Johnston, J. M., Newcomer-Johnson, T. A., Ringold, P. L., Russel, M. J., Sharpe, L. A., \& Yee, S. J. H. (2020). The final ecosystem goods and services (FEGS) approach: A beneficiarycentric method to support. In T. O'Higgins, M. Lago, \& T. H. DeWitt (Eds.), Ecosystembased management, ecosystem services and aquatic biodiversity: Theory, tools and applications (pp. 127-148). Amsterdam: Springer.

Dudgeon, D., Arthington, A. H., Gessner, M. O., Kawabata, Z. I., Knowler, D. J., Lévêque, C., Naiman, R. J., Prier-Richard, A. H., Soto, D., Stiassny, M. L. J., \& Sullivan, C. A. (2007). Freshwater biodiversity: Importance, threats status and conservation challenges. Biological Reviews, 81, 163-182.

EC. (2015). Report from the commission to the European Parliament and the council the mid term review of the EU Biodiversity Strategy. COM, 478 final.

EEA. (2010). 10 messages for 2010 freshwater ecosystems (p. 14). Copenhagen, Denmark: European Environment Agency.

Ehrlich, P. R. (1968). The population bomb (p. 223). New York: Ballating Books.

Ehrlich, P. R., \& Holdren, J. P. (1971). Impact of population growth. Science, 171, 1212-1217.

Elliott, M., \& O'Higgins, T. G. (2020). From the DPSIR, the D(A)PSI(W)R(M) emerges... a butterfly- 'protecting the natural stuff and delivering the human stuff'. In T. O'Higgins, M. Lago, \& T. H. DeWitt (Eds.), Ecosystem-based management, ecosystem services and aquatic biodiversity: Theory, tools and applications (pp. 61-86). Amsterdam: Springer.

Enright, S. R., \& Boetler, B. (2020). The ecosystem approach in international law. In T. O'Higgins, M. Lago, \& T. H. DeWitt (Eds.), Ecosystem-based management, ecosystem services and aquatic biodiversity: Theory, tools and applications (pp. 333-352). Amsterdam: Springer.

Flood, S., O'Higgins, T. G. and Lago, M. (2020). The promise and pitfalls of ecosystem services classification and valuation. In T. O'Higgins, M. Lago, \& T. H. DeWitt (Eds.), Ecosystem-based management, ecosystem services and aquatic biodiversity: Theory, tools and applications (pp. 87-104). Amsterdam: Springer.

Fulford, R. S., Heymans, S. J. J., \& Wu, W. (2020). Mathematical modelling for ecosystem-based management (EBM) and ecosystem goods and services (EGS) assessment. In T. O'Higgins, M. Lago, \& T. H. DeWitt (Eds.) Ecosystem-based management ecosystem services and aquatic biodiversity: Theory, tools and applications (pp. 275-290). Amsterdam: Springer.

Funk, A., O’Higgins, T. G., Borgwardt, F., Trauner, D., \& Hein, T. (2020). Ecosystem-based management to support conservation and restoration efforts in the Danube Basin. In T. O'Higgins, M. Lago, \& T. H. DeWitt (Eds.), Ecosystem-based management, ecosystem services and aquatic biodiversity: Theory, tools and applications (pp. 431-444). Amsterdam: Springer.

Gibble, R., Miller, L., \& Harwell, M. C. (2020). Using stakeholder engagement, translational science and decision support tools for ecosystem-based management in the Florida Everglades. In T. O’Higgins, M. Lago, \& T. H. DeWitt (Eds.), Ecosystem-based management and ecosystem services: Theory, tools and applications (pp. 517-542). Amsterdam: Springer.

Gómez, C. M., Delacámara, G., Arévalo-Torres, J., Barbière, J., Barbosa, A. L., Boteler, B, Culhane, F., et al. (2016). He AQUACROSS innovative concept. Deliverable 3.1, European Union's Horizon 2020 framework programme for research and innovation grant agreement no. 642317.

Halpern, B. S., Walbridge, S., Selkoe, K. A., Kappel, C. V., Micheli, F., D’Agrosa, C., Bruno, J. F., Casey, K. S., Ebert, C., Fox, H. E., Fujita, R., Heinemann, D., Lenihan, H. S., Madin, E. M. P., Perry, M. T., Selig, E. R., Spalding, M., Steneck, R., \& Watson, R. (2008). A global map of human impact on marine ecosystems. Science, 319, 948-952.

Hardin, G. (1968). The tragedy of the commons. Science, 162, 1243-1248.

Hardin, G. (1974). Living on a lifeboat. Bioscience, 24, 561-568. 
Harwell, D. R. (2020). Ecosystem Services in U.S. environmental law and governance for the ecosystem-based management practitioner. In T. O'Higgins, M. Lago, \& T. H. DeWitt (Eds.), Ecosystem-based management, ecosystem services and aquatic biodiversity: Theory, tools, and applications (pp. 373-402). Amsterdam: Springer.

Harwell, M. C., Molleda, J. L., Jackson, C. A., \& Sharpe, L. (2020). Establishing a common framework for strategic communication in ecosystem-based management and the natural sciences. In T. O’Higgins, M. Lago, \& T. H. DeWitt (Eds.), Ecosystem-based management, ecosystem services and aquatic biodiversity: Theory, tools and applications (pp. 165-188). Amsterdam: Springer.

Holling, C. S. (1978). Adaptive environmental assessment and management. Chichester, UK: Wiley.

Johnston, J. M., Zomer, R., \& Mingcheng, W. (2020). Predicting future vegetated landscapes under climate change: Application of the environmental stratification methodology to protected areas in the lower Mekong Basin. In T. O'Higgins, M. Lago, \& T. H. DeWitt (Eds.), Ecosystem-based management, ecosystem services and aquatic biodiversity: Theory, tools and applications (pp. 561-580). Amsterdam: Springer.

Le Tissier, M. (2020). Unravelling the relationship between ecosystem-based management, integrated coastal zone management and marine spatial planning. In T. O'Higgins, M. Lago, \& T. H. DeWitt (Eds.), Ecosystem-based management, ecosystem services and aquatic biodiversity: Theory, tools and applications (pp. 403-416). Amsterdam: Springer.

Lewis, N. S., Marois, D. E., Littles, C. J., \& Fulford, R. S. (2020). Projecting changes to coastal and estuarine ecosystem goods and services- models and tools. In T. O'Higgins, M. Lago, \& T. H. DeWitt (Eds.), Ecosystem-based management, ecosystem services and aquatic biodiversity: Theory, tools and applications (pp. 235-254). Amsterdam: Springer.

Lillebø, A. I., Teixeira, H., Martínez-López, J., Genua-Olmedo, A., Marhubi, A., Delacámara, G., Mattheiß, V., Strosser, P., O’Higgins, T., \& Nogueira, A. A. J. (2020). Mitigating negative unintended impacts on biodiversity in the Natura 2000 Vouga estuary (Ria de Aveiro, Portugal). In T. O'Higgins, M. Lago, \& T. H. DeWitt (Eds.), Ecosystem-based management, ecosystem services and aquatic biodiversity: Theory, tools and applications (pp. 461-498). Amsterdam: Springer.

McDonald, H., Hoffman, H., Ressurreição, A., Röschel, L., Gerdes, H., Lago, M., Boetler, B., \& McFarland, K. (2020). Ecosystem-based management for more effective and equitable marine protected areas: A case study on the Faial-Pico channel marine protected area, Azores. In T. O’Higgins, M. Lago, \& T. H. DeWitt (Eds.), Ecosystem-based management, ecosystem services and aquatic biodiversity: Theory, tools and applications (pp. 499-516). Amsterdam: Springer.

McKane, R. B., Brookes, A. F., Djang, K. S., Halama, J. J., Pettus, P. B., Barnhart, B. L., Russell, M. J., Vache, K. B., \& Bolte, J. B. (2020). An integrated multi-model decision support framework for evaluating ecosystem-based management options for coupled human-natural systems. In T. O'Higgins, M. Lago, \& T. H. DeWitt (Eds.), Ecosystem-based management, ecosystem services and aquatic biodiversity: Theory, tools and applications (pp. 255-274). Amsterdam: Springer.

Myer, M., \& Johnston, J. M. (2020). Models and mapping tools to inform resilience planning after disasters: A case study of hurricane Sandy and Long Island ecosystem services. In T. O'Higgins, M. Lago, \& T. H. DeWitt (Eds.), Ecosystem-based management, ecosystem services and aquatic biodiversity: Theory, tools and applications (pp. 417-430). Amsterdam: Springer.

O'Hagan, A. M. (2020). Ecosystem-based management (EBM) and ecosystem services in EU law, policy and governance. In T. O’Higgins, M. Lago, \& T. H. DeWitt (Eds.), Ecosystem-based management, ecosystem services and aquatic biodiversity: Theory, tools and applications (pp. 353-372). Amsterdam: Springer.

O'Higgins, T. G., Culhane, F., O’Dwyer, B., Robinson, L., \& Lago, M. (2020). Combining methods to establish potential management measures for invasive species Elodea nutallii in Lough Erne Northern Ireland. In T. O’Higgins, M. Lago, \& T. H. DeWitt (Eds.), Ecosystem- 
based management, ecosystem services and aquatic biodiversity: Theory, tools and applications (pp. 445-460). Amsterdam: Springer.

Östrom, E. (1990). Governing the commons: The evolution of institutions for collective action. Cambridge, UK: Cambridge University Press.

Östrom, E. (2009). A general framework for analyzing sustainability of social-ecological systems. Science, 325, 419-422.

Piet, G., Delacamara, G., Kraan, M., Röckmann, G. C., \& Lago, M. (2020). Advancing aquatic ecosystem-based management with full consideration of the social-ecological system. In T. O'Higgins, M. Lago, \& T. H. DeWitt (Eds.), Ecosystem-based management, ecosystem services and aquatic biodiversity: Theory, tools and applications (pp. 17-38). Amsterdam: Springer.

Robinson, L., \& Culhane, F. (2020). Linkage frameworks: An exploration tool for complex systems. In T. O’Higgins, M. Lago, \& T. H. DeWitt (Eds.), Ecosystem-based management, ecosystem services and aquatic biodiversity: Theory, tools and applications (pp. 213-234). Amsterdam: Springer.

Russell, M. J., Rhodes, C., Sinha, R. K., Van Houtven, G., Warnell, G., \& Harwell, M. C. (2020). Ecosystem-based management and natural capital accounting. In T. O'Higgins, M. Lago, \& T. H. DeWitt (Eds.), Ecosystem-based management, ecosystem services and aquatic biodiversity: Theory, tools and applications (pp. 149-164). Amsterdam: Springer.

Sharpe, L., Hernandez, C., \& Jackson, C. (2020). Prioritizing stakeholders, beneficiaries and environmental attributes: A tool for ecosystem-based management. In T. O'Higgins, M. Lago, \& T. H. DeWitt (Eds.), Ecosystem-based management, ecosystem services and aquatic biodiversity: Theory, tools and applications (pp. 189-212). Amsterdam: Springer.

Williams, K. C., \& Hoffman, J. C. (2020). Remediation to restoration to revitalisation: Ecosystembased management to support community engagement at clean-up sites in the Laurentian Great Lakes. In T. O’Higgins, M. Lago, \& T. H. DeWitt (Eds.), Ecosystem-based management, ecosystem services and aquatic biodiversity: Theory, tools and applications (pp. 543-560). Amsterdam: Springer.

Open Access This chapter is licensed under the terms of the Creative Commons Attribution 4.0 International License (http://creativecommons.org/licenses/by/4.0/), which permits use, sharing, adaptation, distribution and reproduction in any medium or format, as long as you give appropriate credit to the original author(s) and the source, provide a link to the Creative Commons licence and indicate if changes were made.

The images or other third party material in this chapter are included in the chapter's Creative Commons licence, unless indicated otherwise in a credit line to the material. If material is not included in the chapter's Creative Commons licence and your intended use is not permitted by statutory regulation or exceeds the permitted use, you will need to obtain permission directly from the copyright holder.

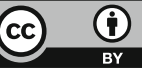

